\title{
SASKATCHEWAN WINTER STONEFLIES
}

\author{
LLOYD DOSDALL, Biology Dept., University of Saskatchewan, Saskatoon, Sask.
}

To anyone not familiar with Saskatchewan's spring and winter fauna, it is amazing to find winter stoneflies or "snow-flies" crawling over the snow or ice along a river bank and actively mating or searching for food in the near-freezing temperatures of early spring. Winter stoneflies are unique among insects because they are most active at temperatures far too cold for many other insects. In fact, chilling temperatures signal the most pronounced growth of winter stonefly nymphs.

Stoneflies are similar to other aquatic insects such as mayflies, caddisflies and dragonflies in which the immature or larval part of their life cycle is spent in water while the adult is terrestrial. However, stoneflies require clean, well-oxygenated water and are, therefore, restricted to streams and rivers in Saskatchewan. Because the nymphs of winter stoneflies feed and grow during the fall and vinter months (September to March), they are restricted to rivers which do not freeze to the bottom.

Winter stonefly nymphs are welladapted to life in cold water. The eggs of several winter stonefly species hatch in the spring immediately after being laid by the female while water temperatures are still cool." Nymphal growth occurs for a short time, but when water temperatures become warm in the summer months, nymphs burrow into the river bottom and spend the summer in a state of suppressed development (diapause). Cool water temperatures in early fall signal the resumption of nymphal feeding and growth which continues throughout fall and winter. Winter stoneflies generally feed on dead plant material. During the first warm days of spring, when the ice cover breaks in rivers and streams, full-grown nymphs crawl out of the water onto stones on logs and the adults emerge from the nymphal skin. Males generally emerge a few days before females, and mating can occur almost immediately. In fact males have been observed to attach ir a mating position to nymphal females even though the adult female had no yet emerged.

An interesting feature of some win ter stoneflies is the occurrence $o$ brachyptery or short-wingedness especially in males. This is particularly evident in the male of Utacapnia travo (Fig. 4), the male of Paracapnic angulata (Fig. 6) and the male o Oemopteryx fosketti (Fig. 12). Wher brachyptery occurs, it is restricted tc males in Saskatchewan species, but i has been known to occur in both male: and females of some species found out side the province. Male stoneflie: usually emerge earlier than female: and by having nonfunctional shor wings, they are prevented from bein? carried away from the emergence sit by wind before the females emerge.

Because adult winter stoneflies hav poorly developed mouthparts and ar short-lived compared to many othe adult insects, it was long thought tha adults did not feed. Closer study however, has shown that many specie feed on lichens and algae which occu on tree trunks bordering streams.

Adult stoneflies are easily collecter in late March and early April by sim ply picking them off the surface of th snow, the sides of bridges, or from tre trunks along the streams from whicl they have emerged. Adults may also b found under stones or trash at th water's edge. An aerial sweep net cai be used to beat brush or tree branche to dislodge adults. Nymphs are bes collected by holding a sweep net in thi water and kicking stones with one' 


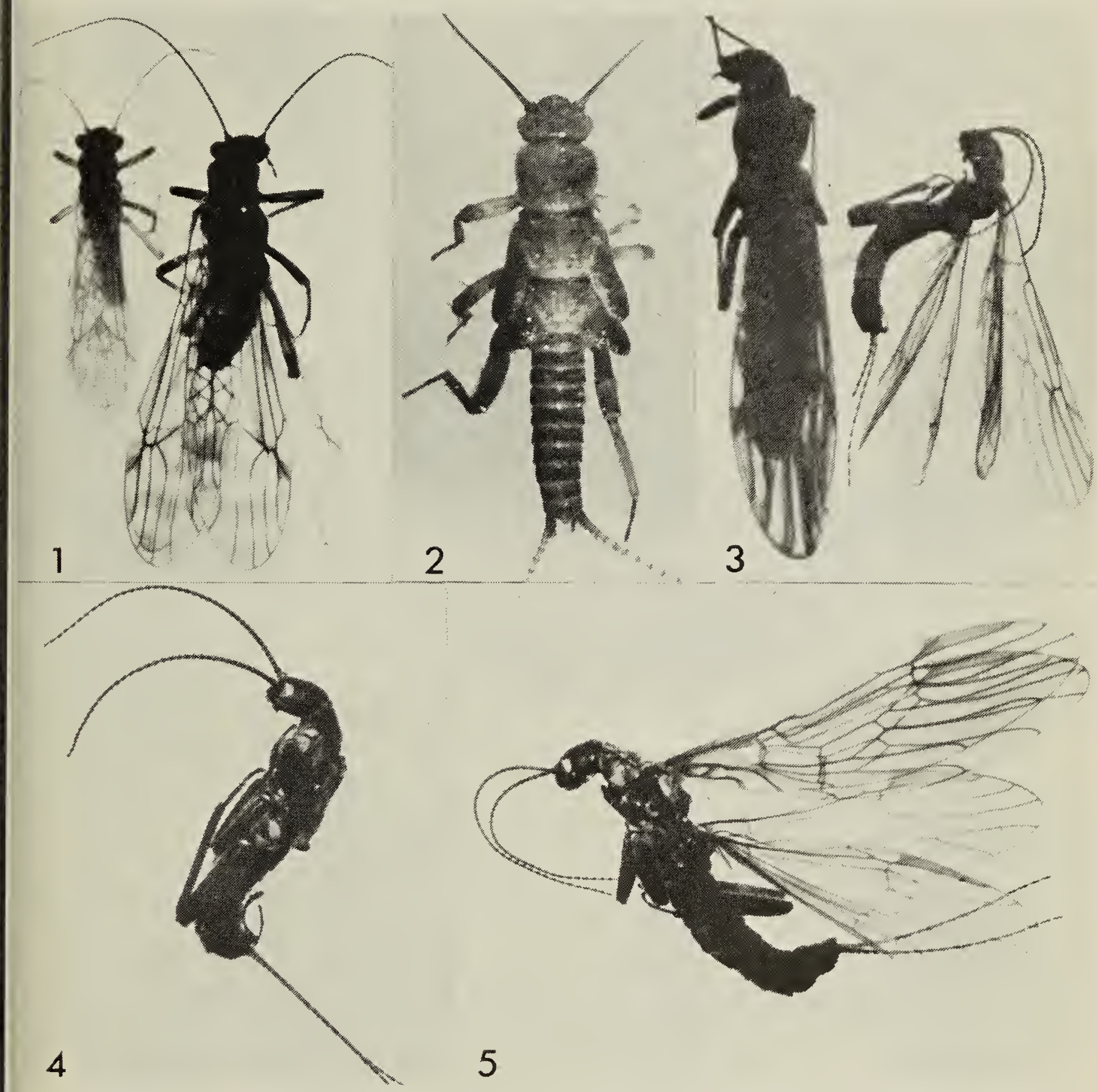

Figs. 1-5. Saskatchewan winter stonefly species. 1. Male (left) and female (right) of Zapada cinctipes (average length $=1 \mathrm{~cm}$.). Stonefly females are generally larger in size; this species has a banded pattern on the wings; 2 . Mature nymph of $Z$. cinctipes; 3 . Female (left) and male (right) of Capnia confusa (average length $=6 \mathrm{~mm}$.); 4 . Male of Utacapnia trava: 5 . Female of U. trava. 


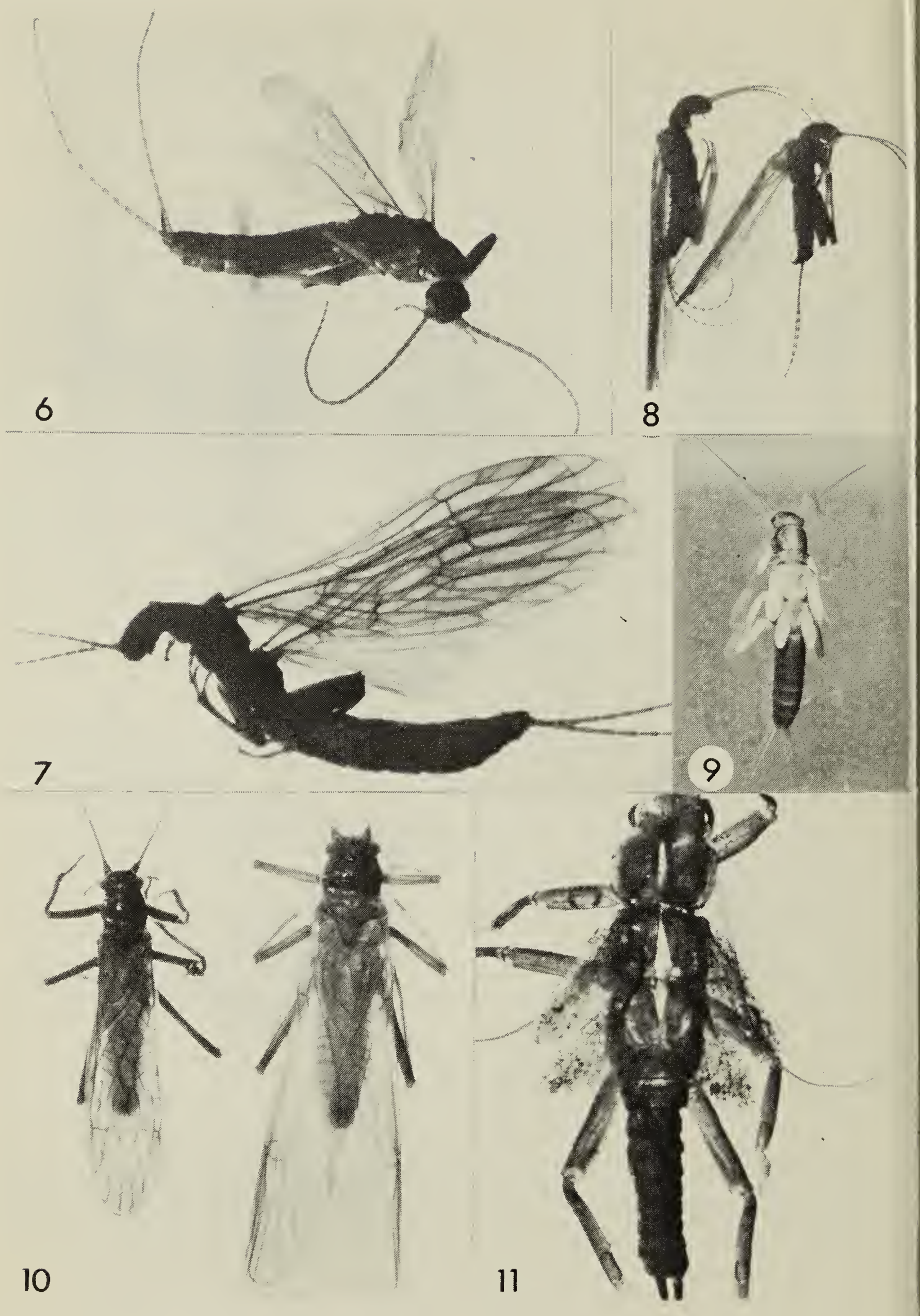

Figs. 6-11. Common Saskatchewan winter stonefly species. 6. Male of Paracapnia angulatc (length $=4 \mathrm{~mm}$.); 7 . Female of $P$. angulata (length $=8 \mathrm{~mm}$.); 8 . Female (left) anc male (right) of Capnia gracilaria (average length $=5 \mathrm{~mm}$.): 9. Mature nymph of $C$ gracilaria: 10. Male (left) and female (right) of Taeniopteryx nivalis (average length $=$ $15 \mathrm{~mm}$. ); 11 . Nymphal cast skin of $T$. nivalis. 


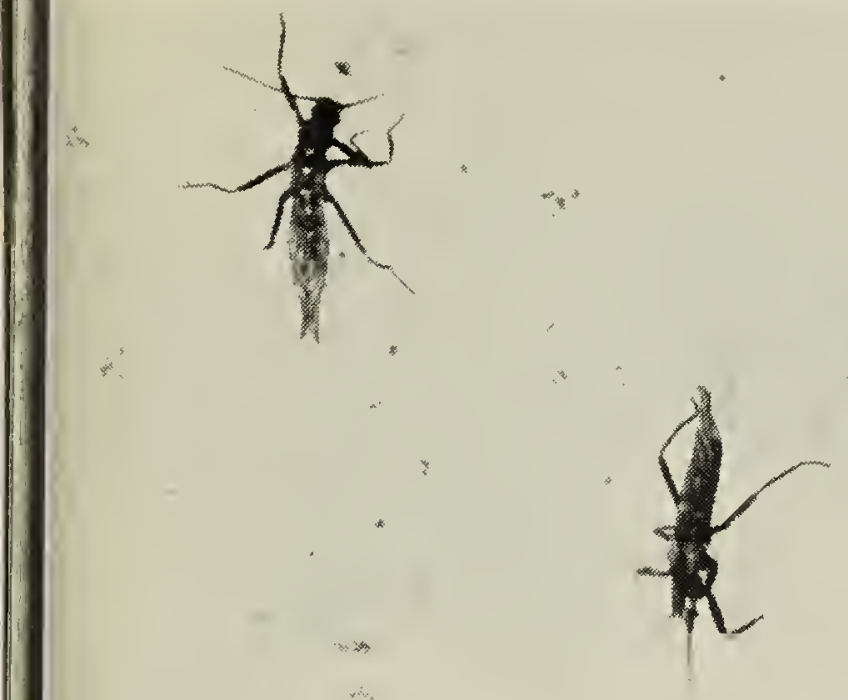

12
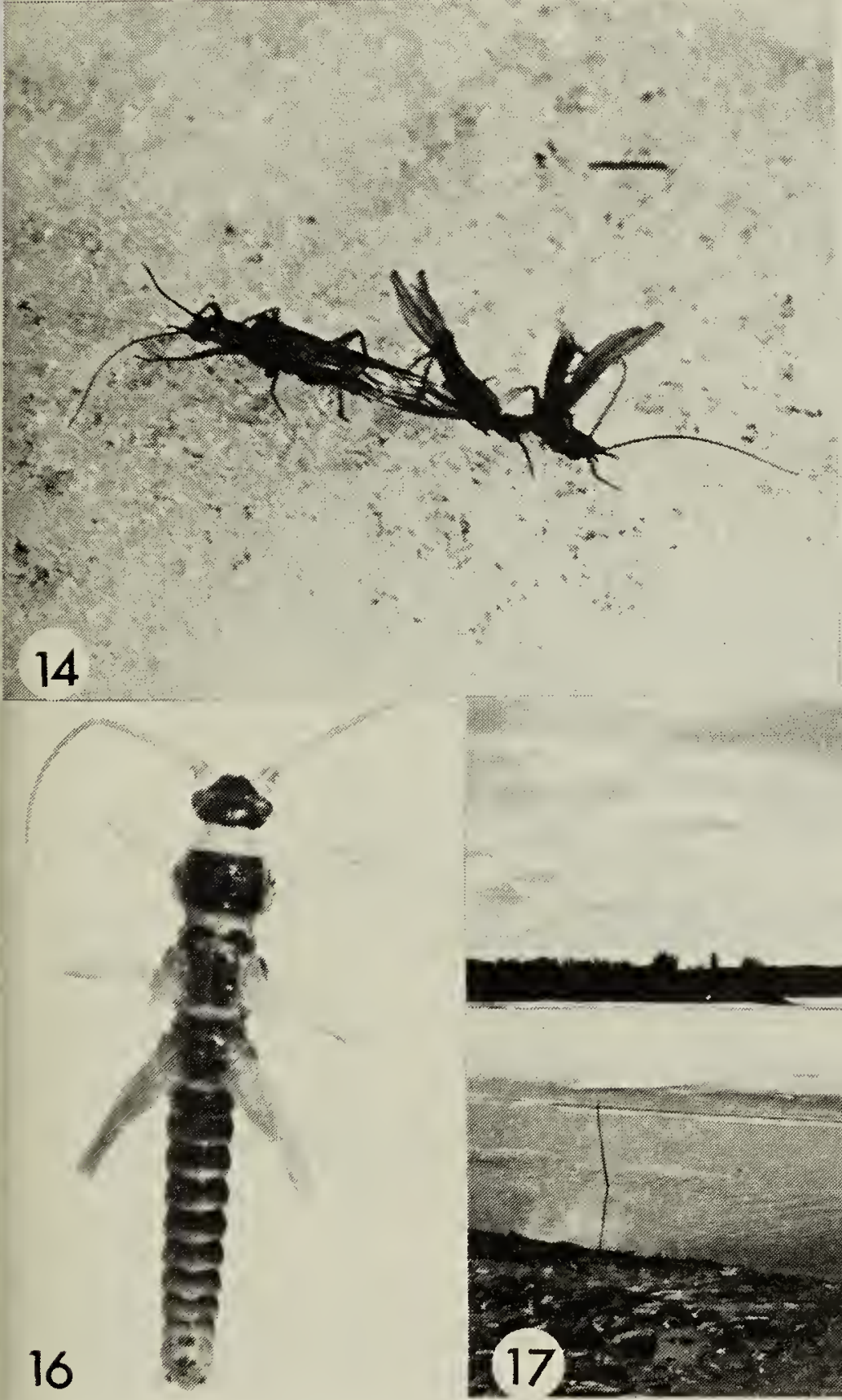
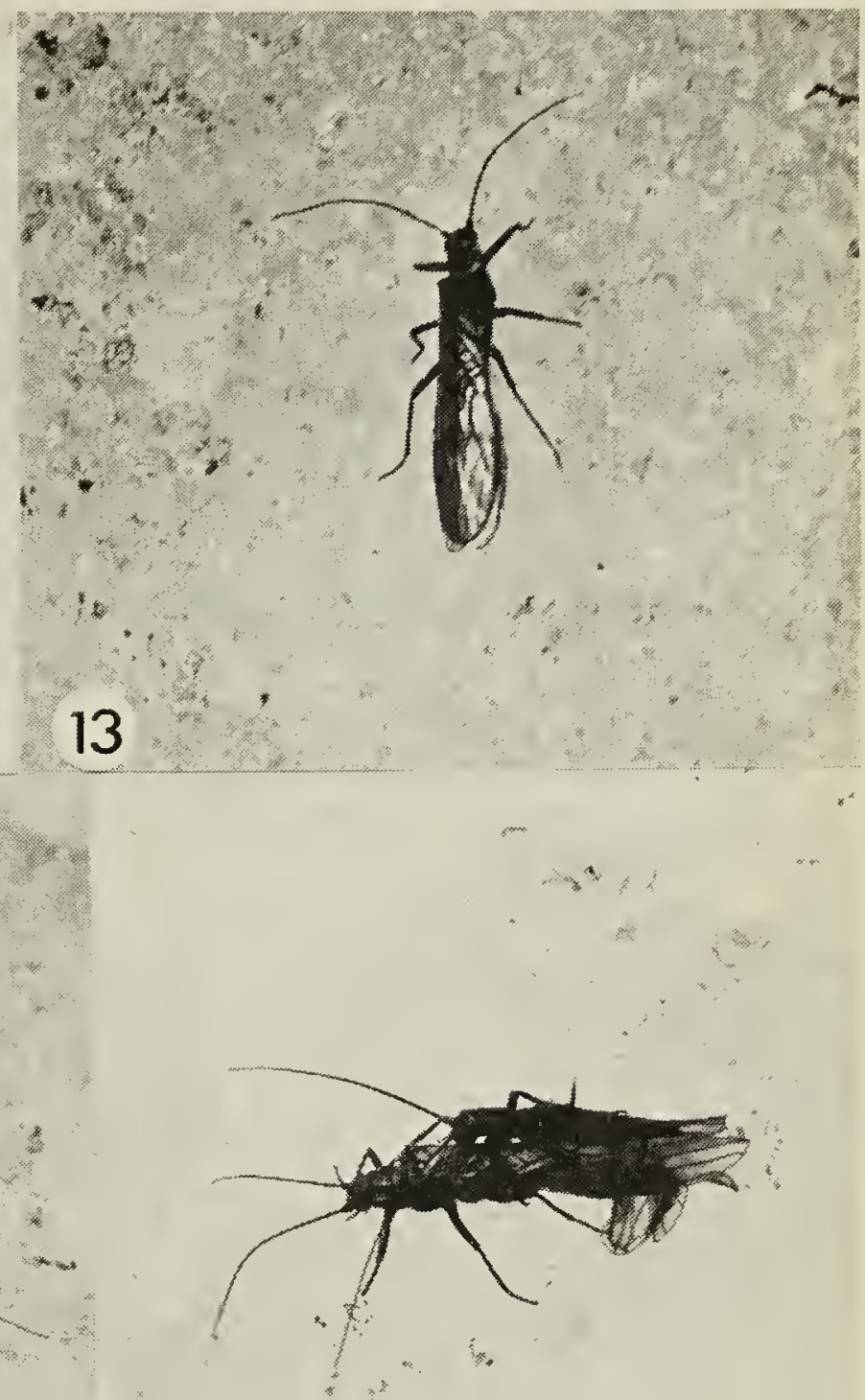

15

Figs. 12-17. 12. Two males of Oemopteryx fosketti (length $=8 \mathrm{~mm}$.) actively searching out females on the snow near the North Saskatchewan River, 13. female of $O$. fosketti; 14 A single female and two males of $O$. fosketti; 15. Mating pair of $O$. fosketti on the snow; 16. Nymphal male of $O$. fosketti; 17. North Saskatchewan River at the time of emergence of $O$. fosketti. 
feet to dislodge numphs which are then carried by the current into the net. Both nymphs and adults should be preserved in 80 to $95 \%$ ethyl alcohol with accurate locality and date of collection labels.

Acknowledgments: I thank the Institute for Northern Studies and Dr. D. M. Lehmkuhl for financial support and I am grateful to John Waddington and Elaine Dribnenky for assistance in preparing the photographs. For comments on the manuscript, I thank Drs. D. M. Lehmkuhl and F. E. Wait.

\section{Additional Reading:}

'FRISON, T. H. 1929. Fall and winter stoneflies, or Plecoptera, of Illinois. Bull. Illinois Nat. Hist. Surv. 18: 345-409.

'HARPER, P. P. and H. B. N. HYNES. 1970. Diapause in the nymphs of Canadian winter stoneflies. Ecology 51: 925-927.

"HITCHCOCK, S. W. 1974. The Plecoptera or stoneflies of Connecticut. Bull. Connecticut Geol. Nat. Hist. Surv. 107: 1-262.

'LEHMKUHL, D. M. 1975. Field guide to aquatic insect families. Blue Jay 33: 199-219.
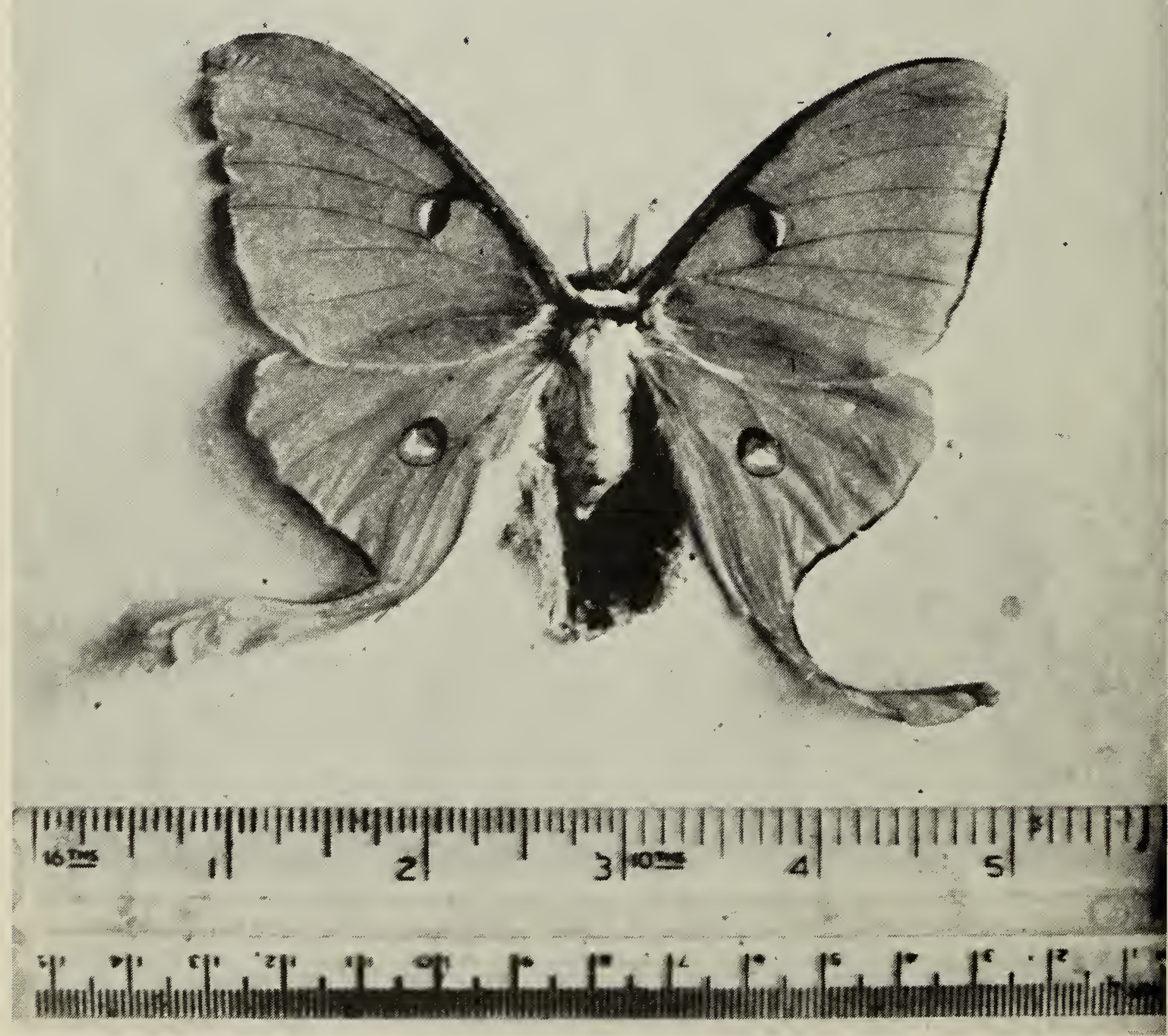